\title{
Reseña de Mouffe, Chantal. (2016). La paradoja democrática. El peligro del consenso en la politica contemporánea. Barcelona: Gedisa.
}

\author{
Minerva AnTe LeZAMA \\ Facultad de Filosofía y Letras, \\ Universidad Nacional Autónoma de México \\ México
}

La paradoja democrática encierra una serie de análisis sobre lo problemático de las democracias modernas, relacionado con las lógicas del ejercicio del poder en tanto cualidad humana y colectiva en el campo político. Mouffe argumenta en distintos momentos su tesis central sobre el consenso en la democracia (o falso consenso) como encubridor y represor del antagonismo político y de la pluralidad constitutiva de lo social. Como ella misma lo indica, la democracia agonística "exige la aceptación de que el conflicto y la división son inherentes a la política y de que no hay ningún lugar en el que pueda alcanzarse definitivamente una reconciliación en el sentido de una plena actualización de la unidad del "pueblo"' (Mouffe, 2016: 32). Lejos de ensombrecer nuestra perspectiva hacia futuro, Mouffe, a partir de una aguda y por momentos reiterativa crítica a los problemas democráticos, estimula nuestra reflexión invitándonos a la creatividad política pero siempre partiendo del reconocimiento de la irreductibilidad de nuestra naturaleza plural y conflictiva. "[I]maginar que la democracia pluralista podría llegar a ser algún día un sistema perfectamente articulado es transformarla en un ideal que se refuta a sí mismo, ya que la condición de posibilidad de una democracia pluralista es al mismo tiempo la condición de imposibilidad de su perfecta puesta en práctica. De ahí la importancia de reconocer su naturaleza paradójica" (Mouffe, 2016: 32).

Cabe mencionar que el libro implicó un ejercicio curatorial de cinco ensayos realizados en momentos distintos entre 1995 y 2000, introducidos y concluidos por la autora en 2000 y prologados para su edición en español por Jorge Alemán en 2016. En el primer capítulo, problematiza la democracia y establece sus conexiones con el poder y "lo político". Un par de frases que detonan su análisis son "toda objetividad social está constituida por actos de poder" (Mouffe, 2016: 38) y "toda identidad resulta puramente contingente" (Mouffe, 2016: 39). En el capítulo 2, centra su argumentación en torno a dos asuntos: los límites de la ciudadanía y la naturaleza del consenso liberal democrático y su crítica a las ideas de Carl Schmit son notorias. En el tercer capítulo, 
las nociones planteadas por Wittgenstein en torno al lenguaje son discutidas por Mouffe como alternativa a enfoques racionalistas que encasillan a la teoría política con sus perspectivas homogeneizadoras y universalistas. En el capítulo 4 plantea las coordenadas para un modelo agonístico, partiendo del análisis de los planteamientos de John Rawls y Jurgen Habermas en torno a una potencial reconciliación entre la democracia y el liberalismo. Finalmente, en el quinto capítulo dedica una severa crítica a la Tercera vía empujada por Tony Blair en el Reino Unido, enfatizando su carácter despolitizador.

Mouffe parte de la contradicción y la necesidad de articulación entre dos tradiciones que basamentan el campo político de nuestras sociedades: 1) la tradición liberal, que implica el llamado imperio de la ley, posiciona los derechos humanos y representa los valores individuales; y 2) la tradición democrática, basada en la igualdad, la identidad entre gobernantes y gobernados y la soberanía popular - la primera en tanto tendencia dominante, la segunda volviendo a emerger-. Ambas perspectivas, de acuerdo con Mouffe, han estado imbricadas históricamente y se afectan entre sí. La autora revisa tanto los teóricos liberales que inspiraron el giro al centro de la socialdemocracia, como los teóricos reaccionarios que permitieron elaborar el crecimiento en Europa, y ahora en América Latina, de los partidos ultraderechistas. Posicionándose claramente como mujer de izquierda, Mouffe plantea la vigencia y relevancia de las categorías izquierda y derecha, desentrañando los peligros que implica el borramiento de sus fronteras y de las posturas que implican una imposible neutralidad.

El pluralismo agonístico, los retos de la ciudadanía, la importancia de robustecer las instituciones, la aceptación del conflicto y su negativa a suprimirlo mediante formas autoritarias, la imposibilidad de consenso, el reconocimiento de las desigualdades en el poder y de éste como constitutivo de la identidad individual y colectiva, se dan cita en las páginas de La paradoja democrática. El pluralismo agonístico de Mouffe plantea una política de agonistas, de reconocimiento y respeto de los adversarios, de enemigos amistosos, enemigos porque buscan organizar un espacio simbólico común de un modo diferente, cuyas ideas se pueden o deben combatir, pero nunca su derecho a defenderlas. Plantea una política de hegemonías salientes a distintos tiempos que no anulan a los adversarios, sino que tienden a un equilibrio del poder, no al arrebatamiento del mismo. Importantes análisis en torno a la desvinculación de ciertos sectores de la población con la ciudadanía y la democracia rondan su libro: la tendencia a la unidimensionalidad política, eliminando toda posibilidad de transformación de las relaciones de poder; el debilitamiento de las instituciones, situación ante la que nos invita a robustecerlas y defenderlas; la imposibilidad para identificarse con los conceptos de ciudadanía desencadenantes de otras formas de identificación colectiva fundamentalistas de tipo religioso, moral y ético. Mouffe encuentra la suma relevancia del empujar posibilidades democráticas que se centren en construir formas de poder más compatibles con los valores democráticos, enfatizando "lo político" como la dimensión de antagonismo inherente a las relaciones humanas y "la política" como el campo simbólico de prácticas, discursos e instituciones, conflictivo y diverso, afectado por lo 
político y que en respuesta busca "domesticarlo". Dichas posibilidades no son suficientemente captadas por intentos como el de la democracia deliberativa.

A modo de punta del rebozo analítico que va tejiendo Mouffe, entran en escena Žižek (1992) y Derrida (1997) con sus planteamientos tocantes a la imposible reconciliación democrática: la irreductibilidad es una cualidad de la multiplicidad de ideas, tanto como la indecibilidad, que implican la ausencia de que podremos estar completamente satisfechos y seguros de haber realizado una buena elección, puesto que ésta, en tanto decisión entre las alternativas posibles, se producirá siempre en detrimento de las otras. Mouffe enfatiza que esa pluralidad social y política que se puede traducir en inestabilidad y caos es irreductible mediante un cálculo racional "pero esto es a un tiempo un riesgo y una oportunidad, ya que una continua estabilidad significaría el fin de la política y la ética" (147). Mouffe cree que sólo aceptando la paradoja democrática podremos considerar el modo de enfrentarnos a ella.

Esta reseña representa una instantánea del pensamiento de Mouffe que merece ser explorado en un México en el que vivimos un momento parecido al alebrije: discursivamente la soberanía popular se ha posicionado desde el gobierno federal, al igual que los derechos humanos, los que aparecen fuertemente adoptados desde el sexenio atrás en la planeación y programación nacionales. Sin embargo, en realidad se vieron atrozmente vulnerados de forma diferenciada en diversos sectores poblacionales y el pase de estafeta de la derecha a la izquierda representó la utopía gubernamental deseada por muchos de nuestros padres pero también está representando una forma de desencantamiento al estilo Weber (como lo plantea Mouffe); en el que las instituciones le abrieron paso a personas provenientes de la ciencia, el activismo, las academias, y la toma de la sede de la Comisión Nacional de Derechos Humanos por algunos grupos de mujeres activistas nos lleva a reflexiones posibles que, diría Mouffe, tenemos que discutir y planear colectiva y agonísticamente para el futuro de nuestras problemáticas democracias.

\section{Referencias bibliográficas}

Derrida, Jacques (1997). The Politics of Friendship (Phronesis S.). Londres: Verso. Žižek, Slavoj. (1992). Enjoy Your Symptom!: Jacques Lacan in Hollywood and Out. Londres: Routledge. 